phys. stat. sol. (a) 26, 561 (1974)

Subject classification: $14.4 .1 ; 22.8 .1$

Department of Chemical Engineering, Twente University of Technology,

Laboratory of Inorganic Chemistry and Materials Science, Enschede

\title{
Grain Size Effects on the Ferroelectric-Paraelectric Transition, the Dielectric Constant, and the Lattice Parameters in Lanthana-Substituted Lead Titanate
}

By

\author{
K. KeIZER and A. J. BurgGraAF
}

\begin{abstract}
The effect of the grain size on unit-cell dimensions and dielectric properties has been studied in ceramic lanthana-substituted lead titanate of the general composition $\mathrm{Pb}_{1-\alpha x} \mathrm{La}_{x} \mathrm{TiO}_{3+x(1.5-\alpha)}$ with $\alpha=1.20$ and $x=0.07$ (PLT7) and $x=0.18$ (PLT18). The grain size ranges from 0.6 to $11 \mu \mathrm{m}$ and the effects are most pronounced on the smaller sizes. The tetragonal distortion, characterized by the ratio $c / a$ of the unit-cell dimensions $c$ and $a$, decreases by decreasing grain size. This effect becomes relatively smaller by decreasing temperature. A decrease of the grain size leads to a decrease of the maximum value of the dielectric constant $\varepsilon^{\prime}$ at the Curie temperature $T_{\mathrm{c}}^{\prime}$ and to an increase of $\varepsilon^{\prime}$ at lower temperatures. The Curie temperature shifts to a lower temperature while the phase transition is less sharp with decreasing grain size. The results can be discussed in terms of an average value of internal compression stresses in the direction of the $c$-axis of the crystal.
\end{abstract}

In Lanthan-dotiertem Bleititanat der Zusammensetzung $\mathrm{Pb}_{1-\alpha x} \mathrm{La}_{x} \mathrm{TiO}_{3+x}(1,5-\alpha)$, mit $\alpha=1,20$ und $x=0,07$ (PLT7) und $x=0,18$ (PLT18) wurde der Einfluß der Korngröße auf die Gitterkonstanten und auf das dielektrische Verhalten bestimmt. Der Effekt ist um so größer, je kleiner die mittlere Korngröße ist. Die Korngröße wurde von 0,6 bis $11 \mu \mathrm{m}$ variiert. Das Maß der tetragonalen Verzerrung, dargestellt durch das Verhältnis $c / a$ der Gitterkonstanten $c$ und $a$, wird mit abnehmender Korngröße kleiner. Der Einfluß wird bei niedrigeren Temperaturen relativ gering. Das Maximum der Dielektrizitätskonstante $\varepsilon_{\max }^{\prime}$ im Curiepunkt liegt niedriger, und die Dielektrizitätskonstante in der ferroelektrischen Phase ist um so höher, je kleiner die mittlere Korngröße ist. Die Curietemperatur $T_{\mathrm{c}}^{\prime}$ wird niedriger und der Umwandlungspunkt um so unschärfer, je kleiner die Körner sind. Die Resultate sind dann erklärbar, wenn ein positiver Mittelwert der internen Spannung in der Richtung der Gitterkonstante $c$ angenommen wird.

\section{Introduction}

The effect of the grain size on the ferroelectric-paraelectric transition (FPT), the dielectric constant $\varepsilon^{\prime}$, and the lattice parameters has been investigated extensively in the system $\mathrm{BaTiO}_{3}[1$ to 7]. Here the effect of the grain size is attributed to internal stresses, which appear if the domains and the grains are of comparable sizes.

In describing the grain size effect in a quantitative manner Buessem et al. [4] as well as Micheron and Godefroy [5] have designed models, which are based on the Devonshiretheory [8]. In this thermodynamic model the elastic Gibbs' function $G$ is expanded in terms of the polarization $P$ as well as in terms of the internal stress $S$.

In materials other than $\mathrm{BaTiO}_{3}$ only very few investigations have been made to determine the grain size effect on the dielectric properties. The effect of the 
grain size on the ferroelectric-paraelectric transition (FPT) has been recently investigated in the lanthana-substituted leadzirconate-leadtitanate system [9]. These measurements cannot be evaluated however because of possible inhomogeneities and because X-ray data is not incorporated in the results.

In some cases the results of the dielectric measurements have been explained by assuming the existence of stress effects on a microscale [10 to 12]. These stresses should operate on very small domains with different composition. However the existence of a stress effect on the dielectric properties on a macroscale (e.g. by grain size variation) has never shown in these systems.

In this paper the effect of the grain size on the dielectric constant around the FPT and in the ferroelectric phase of lanthana-substituted leadtitanate (PLT) has been investigated. Changes in the unit-cell dimensions as a function of the grain size have been considered as an indication of strains induced by stresses.

\section{Experimental Procedure}

\subsection{Preparation}

The samples were prepared by means of a normal sintering procedure and a hot-pressing procedure. The general composition of the samples is $\mathrm{Pb}_{1-\alpha x} \mathrm{La}_{x} \mathrm{TiO}_{3+x(1.5-a)}$ with $\alpha=1.20 \pm 0.05$ and $x=0.07$ (PLT7) or $x=0.18$ (PLT18). The La/Ti ratio was determined by X-ray fluorescence analysis. The lead elimination parameter $\alpha$ has been discussed by Hennings and Härdtl [13] and was determined by gravimetric analysis. The raw materials $\mathrm{PbO}$ and $\mathrm{TiO}_{2}$ were dried at $150{ }^{\circ} \mathrm{C}$ and $\mathrm{La}_{2} \mathrm{O}_{3}$ at $850^{\circ} \mathrm{C}$.

After mixing, calcining at $850^{\circ} \mathrm{C}$ during $16 \mathrm{~h}$, ball-milling and isostatically pressing at 4000 bar all samples were sintered at $1260{ }^{\circ} \mathrm{C}$ during $16 \mathrm{~h}$ in an atmosphere of pure oxygen. A part of the sintered material was milled for $8 \mathrm{~h}$ in water and after this milling procedure the average particle size of the powder is $(0.6 \pm 0.1) \mu \mathrm{m}$. This powder was sintered at $1130{ }^{\circ} \mathrm{C}$ during $16 \mathrm{~h}$ or hotpressed at $980^{\circ} \mathrm{C}$ during $30 \mathrm{~min}$. The density of all samples is better than $98 \%$ of the theoretical value.

From the sintered samples dises were made with a diameter of $6 \mathrm{~mm}$ and a thickness of $0.5 \mathrm{~mm}$. To avoid stresses which are not introduced by grain size effects the dises were annealed at $900{ }^{\circ} \mathrm{C}$ during $2 \mathrm{~h}$ in an oxygen atmosphere and then cooled down slowly. After this annealing procedure the results for the hot-pressed samples were not reproducible. Therefore these samples were annealed for a second time at a temperature of $40^{\circ} \mathrm{C}$ above the hot-pressing temperature of $980^{\circ} \mathrm{C}$ during $30 \mathrm{~min}$ in an oxygen atmosphere and then cooled down slowly. Now results were reproducible.

\subsection{Measurements}

The average grain size value was calculated from the line-intercept method using scanning electron microscope photographs. The calculated values were multiplied by 1.56 to get the correct values of the grain size [14].

The lattice constants were measured by a Philips X-ray diffractometer and a high temperature Guinier camera using powders with a particle size of about $30 \mu \mathrm{m}$ obtained by milling sintered samples. An annealing procedure at $600{ }^{\circ} \mathrm{C}$ during $2 \mathrm{~h}$ was used for the milled samples. In some cases ceramic discs were used to compare the results with the mentioned powders. 


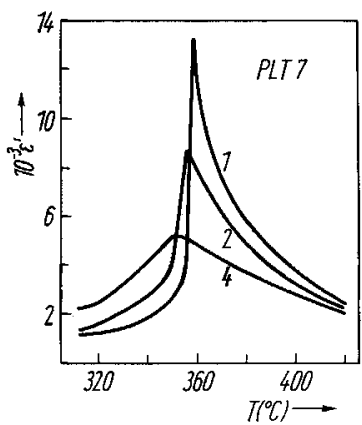

Fig. 1. The effect of the grain size on the dielectric constant $\varepsilon^{\prime}$ of PLT7 at the ferroelectric-paraelectric transition (sample No see Table 1)

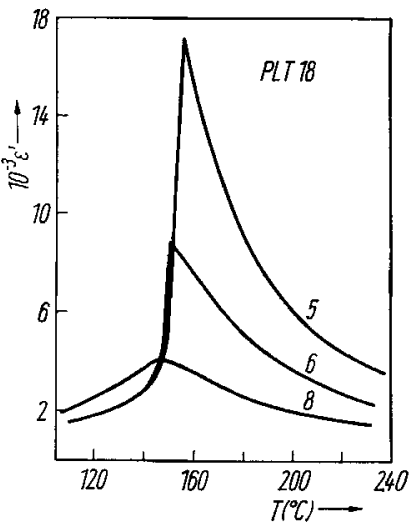

Fig. 2. The effect of the grain size on the dielectric constant $\varepsilon^{\prime}$ of PLT18 at the FPT (sample No see Table 1)

A Wayne Kerr Universal Bridge type B221 was used to measure the capacity and the conductivity of the samples at $10 \mathrm{kHz}$. The heating and cooling rates varied between 0.5 and $2.0 \mathrm{deg} / \mathrm{min}$. The measured values of the capacity and the conductivity appeared to be independent of the rates used.

\section{Results}

\subsection{Dielectric results}

In Fig. 1 and 2] the" dielectric constant of PLT7 and PLT18 samples respectively is shown during heating in the temperature range around the FPT as a function of the grain size. There is a temperature hysteresis of 2 to $5 \mathrm{deg}$ between the heating and the cooling curves at the transition. With decreasing grain size the Curie temperature ${ }^{1}$ ) as well as the maximum value of the dielectric constant $\varepsilon_{\max }^{\prime}$ decreases [15].

Table 1 shows the maximum value of the dielectric constant $\varepsilon_{\max }^{\prime}$, the Curie temperature $T_{\mathbf{c}}^{\prime}$, the maximum value of the dielectric losses $\varepsilon_{\max }^{\prime \prime}$, the temperature of loss maximum $T_{\varepsilon^{\prime \prime}}$, and the difference between the two mentioned temperatures as a function of the grain size in PLT7 and PLT18. The maximum value of the dielectric losses $\varepsilon_{\max }^{\prime \prime}$ was corrected for conduction losses, which are at most $50 \%$ of the value of the total losses. At decreasing grain size $\varepsilon_{\max }^{\prime}$ and $\varepsilon_{\max }^{\prime \prime}$ decrease and $\left(T_{\mathbf{c}}^{\prime}-T_{e^{\prime \prime}}\right)$ increases for both PLT7 and PLT18.

Table 1 also shows, that there is a difference in $T_{\mathrm{c}}^{\prime}$ between a sample, which is annealed $80^{\circ} \mathrm{C}$ below and the same sample, which is annealed $40^{\circ} \mathrm{C}$ above, the hot-pressing temperature. The second annealing procedure eliminates the stress resulting from the hot-pressing procedure which results in a decrease of the value of $T_{\mathrm{c}}^{\prime}$. The grain size before and after the annealing is the same within the measuring variance. With $\mathrm{X}$-ray diffraction there is no detectable preferred orientation or texture.

1) In all cases the temperature of the maximum value of the dielectric constant is called the apparent Curie temperature $T_{\mathrm{c}}^{\prime}$. 


\section{Table 1}

The maximum values of the dielectric constant $\varepsilon_{\max }^{\prime}$ and the dielectric losses $\varepsilon_{\max }^{\prime \prime}$ of PLT7 and PLT18 and the corresponding temperatures at the FPT

\begin{tabular}{l|l|c|c|c|c|c|c}
\hline sample No. & system & $\begin{array}{c}\text { grain size } \\
(\mu \mathrm{m})\end{array}$ & $10^{-3} \varepsilon_{\max }^{\prime}$ & $\begin{array}{c}T_{\mathrm{c}}^{\prime} \\
\left({ }^{\circ} \mathrm{C}\right)\end{array}$ & $\varepsilon_{\max }^{\prime \prime}$ & $\begin{array}{c}T_{\varepsilon^{\prime \prime}} \\
\left({ }^{\circ} \mathrm{C}\right)\end{array}$ & $\begin{array}{c}T_{\mathrm{c}}^{\prime}-T_{\varepsilon^{\prime \prime}} \\
\left({ }^{\circ} \mathrm{C}\right)\end{array}$ \\
\hline & & & & & & & \\
1 & PLT7 & 3.1 & 13.3 & 357 & 110 & 356 & 1 \\
$\left.3^{*}\right)$ & PLT7 & 1.1 & 9.4 & 355 & 40 & 353 & 2 \\
$\left.4^{* *} *\right)$ & PLT7 & 0.6 & 4.7 & 358 & 20 & 354 & 4 \\
5 & PLT7 & 0.6 & 5.2 & 351 & 15 & 347 & 4 \\
6 & PLT18 & 10.9 & 16.9 & 157 & 100 & 155 & 2 \\
$\left.7^{*}\right)$ & PLT18 & 3.1 & 8.7 & 152 & 75 & 150 & 2 \\
$\left.\left.8^{*}\right) * *\right)$ & PLT18 & 0.8 & 3.7 & 168 & 35 & 155 & 13 \\
& PLT18 & 0.8 & 4.1 & 147 & 45 & 134 & 13
\end{tabular}

*) Hot-pressed samples.

**) Samples annealed at $40^{\circ} \mathrm{C}$ above the hot-pressing temperature.

Table 2

The values of Curie constant and the extrapolated value of $T_{0}$ of PLT7 and PLT18 at the FPT

\begin{tabular}{c|c|c|c|c}
\hline sample No. & $\begin{array}{c}C \\
\left(10^{-5}{ }^{\circ} \mathrm{C}\right)\end{array}$ & $\begin{array}{c}T_{0} \\
\left({ }^{\circ} \mathrm{C}\right)\end{array}$ & $\begin{array}{c}T_{\mathrm{c}}^{\prime} \\
\left({ }^{\circ} \mathrm{C}\right)\end{array}$ & $\begin{array}{c}T_{\mathrm{c}}^{\prime}-T_{0} \\
\left({ }^{\circ} \mathrm{C}\right)\end{array}$ \\
\hline 1 & 2.2 & 343 & 357 & 14 \\
2 & 2.0 & 338 & 355 & 17 \\
3 & 2.2 & 323 & 358 & 35 \\
4 & 2.2 & 321 & 351 & 30 \\
5 & 3.3 & 145 & 157 & 12 \\
6 & 2.2 & 138 & 152 & 14 \\
7 & 2.5 & 106 & 168 & 62 \\
8 & 1.7 & 123 & 147 & 24
\end{tabular}

Table 2 shows the Curie constant $C$, the Curie temperature $T_{\mathrm{c}}^{\prime}$, the extrapolated Curie temperature $T_{0}$ according to the Curie-Weiss law, and the temperature difference $\left(T_{\mathrm{c}}^{\prime}-T_{0}\right)$ as a function of the grain size for PLT7 and PLT18. At decreasing grain size the Curie constant decreases for PLT18 but is constant for PLT7. $T_{\mathrm{c}}^{\prime}$ and $T_{0}$ decrease and the temperature difference $\left(T_{\mathrm{c}}^{\prime}-T_{0}\right)$ increases both for PLT7 and PLT18. The annealing procedure used for the hotpressed samples is very important for the values of the Curie constant and the Curie temperatures. Because of the broadening of the FPT there is a deviation in the Curie-Weiss law of 5 to $30^{\circ} \mathrm{C}$ depending on the grain size (see Fig. 3.)

At decreasing grain size the dielectric constant between room temperature and the FPT increases, but the grain size effects in this region are small compared with $\mathrm{BaTiO}_{3}$ (see Table 3).

\section{$3.2 X-r a y$ results}

The unit-cell of the perovskite phase exhibits a tetragonal distortion at temperatures lower than $T_{\mathrm{c}}^{\prime}$. In Fig. 4 the $c / a$ ratios are shown as a function of temperature. The standard deviation in $c / a$ is 0.0015 . The curves 1 and 4 show the 

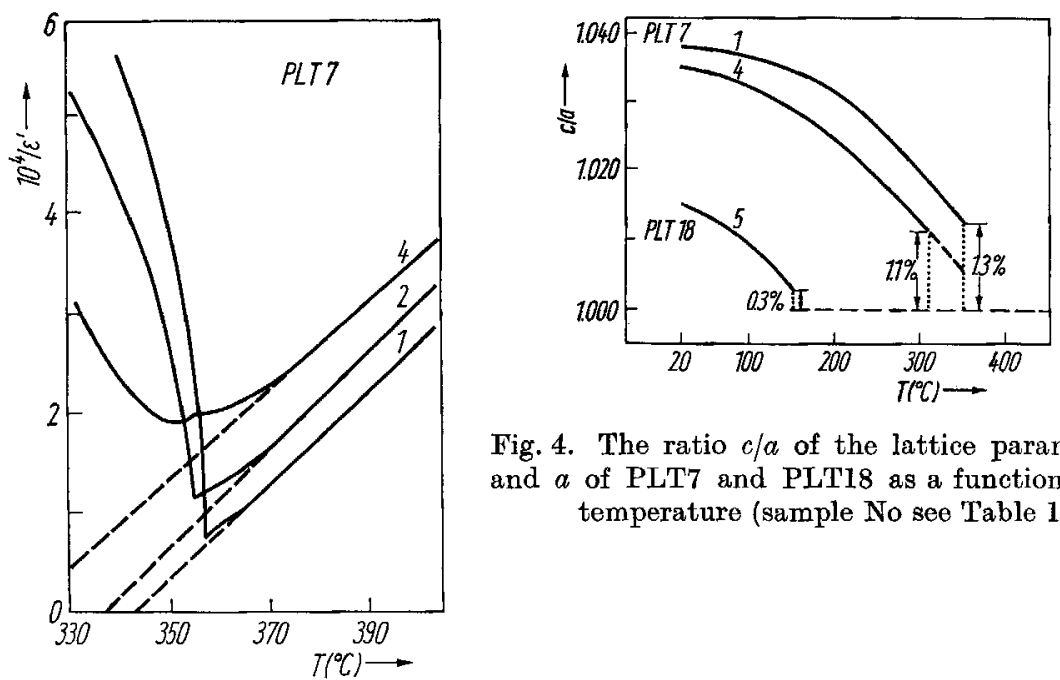

Fig. 4. The ratio $c / a$ of the lattice parameters $c$ and $a$ of PLT7 and PLT18 as a function of the temperature (sample No see Table 1)

Fig. 3. The reciprocal dielectric constant of PLT7 at different grain sizes as a function of the temperature (sample No see Table 1)

differences in this parameter for PLT7 at two extreme grain sizes. It is obvious that over a certain temperature range there is a constant difference in the $c / a$ ratio of about 0.007 which becomes smaller in the lower temperature range. The Curie temperature as indicated by the jump in the curves is situated at a lower temperature for the smallest grain size. For this grain size the temperature of the

Table 3

The difference in physical properties between the largest and smallest grain size of $\mathrm{BaTiO}_{3}$ PLT7 and PLT18, at various temperatures

\begin{tabular}{|c|c|c|c|}
\hline \multirow{2}{*}{$\begin{array}{l}\text { property } \\
\text { differences }\end{array}$} & \multicolumn{3}{|c|}{ material } \\
\hline & $\mathrm{BaTiO}_{3}$ & PLT7 & PLT18 \\
\hline$\left.\Delta \varepsilon_{\max }^{\prime}{ }^{a}\right)$ & -2000 & -8000 & -13000 \\
\hline$\left.\Delta \varepsilon_{20}^{\prime} \mathbf{a}\right)$ & 1600 & 80 & 30 \\
\hline$\left.\Delta \varepsilon_{T^{\prime}}^{\prime}-100^{\mathrm{a}}\right)$ & 1600 & 450 & 130 \\
\hline$\left.\Delta(c / a-1)_{T_{c}^{\prime}}{ }^{b}\right)$ & - & 0.007 & - \\
\hline$\left.\Delta(c / a-1)_{20} b^{b}\right)$ & 0.0015 & 0.003 & 0.005 \\
\hline$\left.(c / a)_{T_{\mathbf{c}}^{\prime}}{ }^{c}\right)$ & 0.005 & 0.013 & 0.003 \\
\hline$\left.\Delta T_{\mathrm{c}}^{\prime}\left({ }^{\circ} \mathrm{C}\right) \mathrm{d}\right)$ & 2 & 6 & 10 \\
\hline
\end{tabular}

a) $\Delta \varepsilon^{\prime}$ difference in the dielectric constant at $T_{\mathrm{c}}^{\prime}, 20^{\circ} \mathrm{C}$ and $\left(T_{\mathrm{c}}^{\prime}-100^{\circ} \mathrm{C}\right)$, respectively.

b) $\Delta(c / a-1)$ difference in the $(c / a-1)$ paramoter at $T_{c}^{\prime}$ and $20{ }^{\circ} \mathrm{C}$, respectively.

$\left.{ }^{c}\right)(c / a)_{T_{0}^{\prime}}^{\prime}$ jump in the lattice constants at $T_{\mathrm{c}}^{\prime}$ for the largest grain size.

d) $\Delta T_{\mathrm{c}}^{\prime}$ difference in $T_{\mathrm{c}}^{\prime}$ 


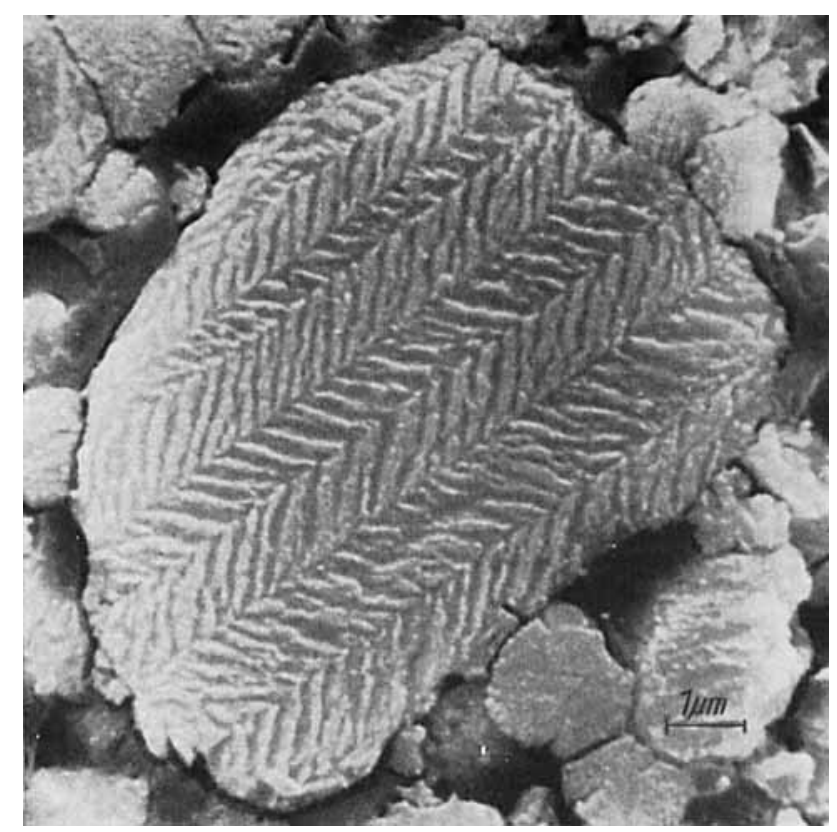

Fig. 5. An example of the domain structure of PLT7 in a porous ceramic with exaggerated grain growth

c/a jump is 30 to $40^{\circ} \mathrm{C}$ lower than $T_{\mathrm{c}}^{\prime}$. It is possible that the true $c / a$ jump is at a higher temperature as is indicated by the dashed line. The reflections of the tetragonal phase are broadened and the resolution of the Guinier technique is too small to determine the exact temperature of the $c / a$ jump. For PLT7 the $c / a$ jumps are $(1.10 \pm 0.15) \%$ and $(1.30 \pm 0.15) \%$ for sample 4 and sample 1 , respectively. The volume jumps are at increasing temperature of the same order of magnitude as lead titanate: -0.2 to $-0.3 \AA$. For PLT18 (curve 5) the $c / a$ jump is $(0.30 \pm 0.15) \%$ and the volume jump is smaller than $0.10 \AA$. The resolution of the Guinier technique is too small to measure the lattice constants of PLT18 at small grain sizes near the FPT. At room temperature the difference in the $c / a$ ratios for PLT18 as a function of the grain size is at most 0.005 (see Table 3).

According to the literature the effect of the grain size is expected to be large if the domain size and the grain size are the same. Fig. 5 shows a photograph of a domain patternin this material. The domain size is in at least two dimensions smaller than $1 \mu \mathrm{m}$, which is about equal to the smallest grain size.

\section{Discussion}

\subsection{Grain size effects in terms of internal stresses}

In the foregoing chapter the effect of the grain size on some dielectric properties has been investigated. The experimental results can be interpreted if it can be assumed that smaller grain sizes results in an increasing average value of the internal compression stresses in the samples. Therefore our results are compared with some results in the literature on hydrostatic pressure effects. 
Samara $[16,17]$ reported a decrease of $T_{\mathrm{a}}$ and the Curie constant $C$ with increasing external hydrostatic pressure for polycrystalline samples of $\mathrm{BaTiO}_{3}$ and for both monocrystalline $\mathrm{BaTiO}_{3}$ and $\mathrm{PbTiO}_{3}$. For polycrystalline samples of $\mathrm{BaTiO}_{3}$ the value of $\varepsilon_{\max }^{\prime}$ decreases and the value of $\left(T_{\mathrm{c}}-T_{0}\right)$ increases with increasing hydrostatic pressure.

As has been shown before the same changes in $T_{\mathrm{c}}^{\prime}, C, \varepsilon_{\max }^{\prime}$, and $\left(T_{\mathrm{c}}^{\prime}-T_{0}\right)$ have been achieved for PLT7, PLT18, and $\mathrm{BaTiO}_{3}$ with decreasing grain size (Tables 1 to 3 ). This means that in polycrystalline samples the effect of decreasing grain size on the mentioned physical properties is analogous to the effect of increasing hydrostatic pressure.

At room temperature the changes in the lattice constants as a function of the grain size are different for the $c$-axis and the $a$-axis. For PLT7 the decrease of the value of the $c$-axis with decreasing grain size is 3 to 4 times the increase of the value of the $a$-axis. For PLT1 8 this change of the $c$-axis and $a$-axis differs by a factor 6 to 7 . This result is an indication that in the major part of a polycrystalline sample with small grains the value of a compression stress in the $c$-direction of the crystals, which results in a decrease of the length of the $c$-axis, is much larger than the value of tensile stresses in the $a$-directions.

These two arguments, analogy between hydrostatic pressure and grain size effects and the differences in the changes of the lattice constants, make it reasonable to interpret the effect of the decreasing grain size in terms of an increasing compression stress in the $c$-direction of the crystals. The average absolute value of the stresses along the $a$-directions of the crystal is much smaller. By Buessem [18] a more quantitative picture of stress distribution of this type has been given. In this model the stresses are different for the bulk and the grain boundary region, a condition which is necessary to assume that the vector sum of all stresses over the whole sample remains zero.

Since the FP-transition in PLT7 and PLT18 is of first order, the shift in $T_{\mathrm{e}}$ with pressure (stress) should obey the Clausius-Clapeyron equation!

$$
\frac{\mathrm{d} T_{\mathrm{c}}}{\mathrm{d} p}=\frac{T_{\mathrm{c}} \Delta V}{L}=\frac{\Delta V}{\Delta S},
$$

where $\Delta V$ and $\Delta S$ are the discontinuous changes in volume and entropy at the transition and $L$ is the latent heat. For $\mathrm{BaTiO}_{3}$ the values of $L$ and $\Delta V$ are respectively $(50 \pm 5) \mathrm{cal} \mathrm{mol}^{-1}$ and $-0.062 \AA^{3}$ per unit cell which gives a values for $\mathrm{d} T_{\mathrm{c}} / \mathrm{d} p=-6 \mathrm{deg} / \mathrm{kbar}$ in excellent agreement with the experimental value [19].

For PLT7 and PLT18 the values of $L$ (measured by the authors) are $(34 \pm 6) \mathrm{cal} \mathrm{mol}^{-1}$ and $(11 \pm 5) \mathrm{cal} \mathrm{mol}^{-1}$, respectively. For PLT7 the value of $\Delta V \approx-(0.2$ to 0.3$) \AA^{3}$ per unit cell which results in a calculated value of $\mathrm{d} T_{\mathrm{c}} / \mathrm{d} p \approx-(50$ to 100$) \mathrm{deg} / \mathrm{kbar}$. In spite of some uncertainties in the measurements the value of $\mathrm{d} T_{\mathrm{c}} / \mathrm{d} p$ of PLT7 is considerably larger as that of $\mathrm{PbTiO}_{3}$ ( $-8 \mathrm{deg} / \mathrm{kbar}$ ), which makes the material rather sensitive for stress and grain size effects in the phase transition region.

\subsection{Comparison of the grain size effect at different temperatures and different campositions}

A stronger influence of dielectric behaviour must be expected with an increasing value of the stored mechanical energy in the system. In general one would expect that a larger change in the $c / a$ ratio and unit cell volume as a func- 
tion of the grain size (stress level) corresponds to a higher level of stored mechanical energy, provided no considerable changes in elastic constants occur.

For comparison purposes tabulations were made in Table 3 of several changes in the $c / a$ ratio, shifts in $T_{\mathrm{c}}^{\prime}$, the dielectric constant at $T_{\mathrm{c}}^{\prime}$, at room temperature, and at an arbitrary intermediate temperature $T_{\mathrm{c}}^{\prime}-100$. From this table it can be seen that the grain size effects on the lowering of the dielectric constant at $T_{\mathrm{c}}^{\prime}$ follow the sequence: PLT18 $>\mathrm{PLT} 7>\mathrm{BaTiO}_{3}$. For raising of the dielectric constant at room temperature and at a constant difference with respect to $T_{\mathrm{c}}^{\prime}\left(\right.$ e.g. $\left.\left(T_{\mathrm{c}}^{\prime}-100\right)\right)$ the reverse is true. $\mathrm{BaTiO}_{3}>\mathrm{PLT} 7>\mathrm{PLT18}$. For the absolute change in $(c / a-1)$ at room temperature the sequence is PLT18 $>$ $>$ PLT7 $>\mathrm{BaTiO}_{3}$. This means, that the effect of the grain size on the dielectric constant in the lower temperature range for different materials is opposite to the change in $(c / a-1)$ and to what in a first approximation may be expected.

Values for $(c / a-1)$ changes as a function of grain size and temperature have been measured for PLT7 only (Fig. 4), so that a direct comparison between several materials at $T_{\mathrm{c}}^{\prime}$ cannot at present be made. It is obvious however that in the PLT-system the pronounced grain size (stress) effect on several properties in the temperature range around $T_{\mathrm{c}}^{\prime}$ increases with decreasing tetragonality $(c / a-1)$ of the unstressed (coarse-grained) material. This is the opposite effect as has been suggested by Samara [16] for the shift in $T_{\mathrm{e}}^{\prime}\left(\mathrm{d} T_{\mathrm{e}}^{\prime} / \mathrm{d} p\right)$ in doped $\mathrm{BaTiO}_{3}$.

The strong effect on the broadening of the phase transition and the value of $\varepsilon_{\max }^{\prime}$ at low value of $(c / a-1)$ in this system can be discussed in terms of a distribution of Curie temperatures caused by stress fluctuations. A quantitative calculation with the help of a method originally introduced by Diamond [11] is being made and will be presented at the II. Internationalen. Gemeinschaftstagung "Elektro- und Magnetokeramik" in Baden-Baden, 1974

\section{Conclusions}

1. Grain size effects on the tetragonality factor $(c / a-1)$ and dielectric properties in lanthana-substituted $\mathrm{PbTiO}_{3}$ have been found in both PLT7 and PLT18.

2. The effects on the dielectric properties are most pronounced around the Curie temperature and for PLT18.

3. At temperatures of more than $30^{\circ} \mathrm{C}$ above $T_{\mathrm{c}}^{\prime}$ the dielectric constant is described by a Curie-Weiss law for all samples. In PLT18 the Curie constant changes by a factor two with decreasing grain size.

4. The shift in $T_{\mathrm{c}}^{\prime}$ and $T_{0}$ in fine-grained $(0.8 \mu \mathrm{m})$ ceramic PLT18 with respect to coarse-grained $(10.9 \mu \mathrm{m})$ materials amounts to -10 and $-22^{\circ} \mathrm{C}$, respectively.

5 . The changes in the tetragonal distortion $(c / a-1)$ at room temperature are considerable, 0.005 for PLT18 and 0.003 for PLT7 respectively, but are not accompanied by strong changes in the value of the dielectric constant at this temperature.

6. The grain size effects in the PLT-materials are consistent with the effects of external hydrostatic pressure on ceramic $\mathrm{BaTiO}_{3}$ and may be interpreted in terms of internal compression stress distribution. 


\section{References}

[1] H. Kniepkamp and W. Heywang, Z. angew. Phys. 6, 385 (1954).

[2] M. Anliker, H. BrugGer, and W. Känzig, Helv, phys. Acta 27, 99 (1954).

[3] G. H. Jonker and W. Noorlander, Science of Ceramics, Ed. G. H. SteWart, Vol. 1, Academic Press, London 1962 (p. 255).

[4] W. R. Buessem, L. E. Cross, and A. K. Goswami, J. Amer. Ceram. Soc. 49, 33 (1966).

[5] F. Micheron and L. Godemroy, Proc. 1st European Meeting on Ferroelectricity, Saarbrücken 1969 (p. 333).

[6] F. Mrcheron, Rev. Techn. Thomson-CSF 4, 5 (1972).

[7] M. KAHN, J. Amer. Ceram. Soc. 54, 455 (1971).

[8] A F. Devonshire, Phil. Mag. 40, 1040 (1949); 42, 1065 (1951); Adv. Phys. 3, 85 (1954).

[9] K. Okazaki and K. Nagata, J. Amer. Ceram Soc. 56, 82 (1973); Proc. 3rd Internat. Meeting on Ferroelectricity, Edinburgh 1973 (p. E3)

[10] J. W. SMith and L. E. Cross, Ferroelectrics 1, 137 (1970).

[11] H. Diamond, J. appl. Phys. 32, 909 (1961).

[12] E. Sawaguchi and H. L. Charters, J. Amer. Ceram. Soc. 42, 157 (1959).

[13] D. HenNINGs and K. H. HÄRDTL, phys. stat. sol. (a) 3, 465 (1970).

[14] M. I. Mendelson, J. Amer. Ceram. Soc. 52, 443 (1969).

[15] K. Keizer, J. Bouwma, and A. J. Burgaraas, Proc. 3rd Internat. Meeting on Ferroelectricity Edinburgh 1973 (p. N7).

[16] G. A. Samara, Phys. Rev. 151, 378 (1966).

[17] G. A. Samara, Ferroelectrics 2, 277 (1971).

[18] W. R. Bdessem, Mechanical Properties of Engineering Ceramics, Interscience Publishers, New York 1961.

[19] E. Fatuzzo and W.J. Merz, Ferroelectricity, North-Holland Publ. Co., Amsterdam 1967. 